Yves Demazeau Franco Zambonelli faan M. Corchado lavier Bajo \{Eds.]

\title{
Advances
}

\section{in Practical Applications}

\section{of Heterogeneous}

Multi-Agent Systems

The PAAMS Collection

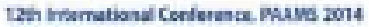

Solareres, Spain, hre 4.6. 2014

Fracedirys

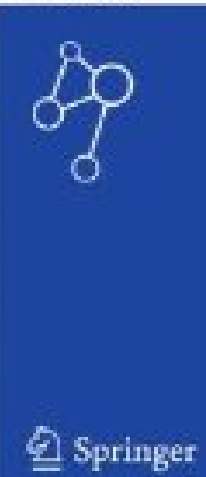




\section{Lecture Notes in Artificial Intelligence 8473}

\section{Subseries of Lecture Notes in Computer Science}

LNAI Series Editors

Randy Goebel

University of Alberta, Edmonton, Canada

Yuzuru Tanaka

Hokkaido University, Sapporo, Japan

Wolfgang Wahlster

DFKI and Saarland University, Saarbrücken, Germany

LNAI Founding Series Editor

Joerg Siekmann

DFKI and Saarland University, Saarbrücken, Germany 
Yves Demazeau Franco Zambonelli

Juan M. Corchado Javier Bajo (Eds.)

\section{Advances \\ in Practical Applications \\ of Heterogeneous \\ Multi-Agent Systems}

The PAAMS Collection

12th International Conference, PAAMS 2014 Salamanca, Spain, June 4-6, 2014

Proceedings

Springer 


\author{
Volume Editors \\ Yves Demazeau \\ Centre National de la Recherche Scientifique \\ Grenoble, France \\ E-mail: yves.demazeau@imag.fr \\ Franco Zambonelli \\ Università degli Studi di Modena e Reggio Emilia \\ Reggio Emilia, Italy \\ E-mail: franco.zambonelli@unimore.it \\ Juan M. Corchado \\ Universidad de Salamanca, Spain \\ E-mail: corchado@usal.es \\ Javier Bajo \\ Universidad Politécnica de Madrid, Spain \\ E-mail: javier.bajo@upm.es
}

ISSN 0302-9743

ISBN 978-3-319-07550-1

DOI 10.1007/978-3-319-07551-8

Springer Cham Heidelberg New York Dordrecht London
e-ISSN 1611-3349

e-ISBN 978-3-319-07551-8

\title{
Library of Congress Control Number: 2014939855
}

\section{LNCS Sublibrary: SL 7 - Artificial Intelligence}

(C) Springer International Publishing Switzerland 2014

This work is subject to copyright. All rights are reserved by the Publisher, whether the whole or part of the material is concerned, specifically the rights of translation, reprinting, reuse of illustrations, recitation, broadcasting, reproduction on microfilms or in any other physical way, and transmission or information storage and retrieval, electronic adaptation, computer software, or by similar or dissimilar methodology now known or hereafter developed. Exempted from this legal reservation are brief excerpts in connection with reviews or scholarly analysis or material supplied specifically for the purpose of being entered and executed on a computer system, for exclusive use by the purchaser of the work. Duplication of this publication or parts thereof is permitted only under the provisions of the Copyright Law of the Publisher's location, in ist current version, and permission for use must always be obtained from Springer. Permissions for use may be obtained through RightsLink at the Copyright Clearance Center. Violations are liable to prosecution under the respective Copyright Law.

The use of general descriptive names, registered names, trademarks, service marks, etc. in this publication does not imply, even in the absence of a specific statement, that such names are exempt from the relevant protective laws and regulations and therefore free for general use.

While the advice and information in this book are believed to be true and accurate at the date of publication, neither the authors nor the editors nor the publisher can accept any legal responsibility for any errors or omissions that may be made. The publisher makes no warranty, express or implied, with respect to the material contained herein.

Typesetting: Camera-ready by author, data conversion by Scientific Publishing Services, Chennai, India

Printed on acid-free paper

Springer is part of Springer Science+Business Media (www.springer.com) 


\section{Preface}

Research on agents and multi-agent systems has matured during the last decade and many effective applications of this technology are now deployed. An international forum to present and discuss the latest scientific developments and their effective applications, to assess the impact of the approach, and to facilitate technology transfer, has become a necessity and was created a few years ago.

PAAMS, the International Conference on Practical Applications of Agents and Multi-Agent Systems, is the international yearly event for presenting, discussing, and disseminating the latest developments and the most important outcomes related to real-world applications. It provides a unique opportunity to bring multi-disciplinary experts, academics, and practitioners together to exchange their experience in the development and deployment of agents and multiagent systems.

This volume presents the papers that were accepted for the 2014 edition of PAAMS. These articles report on the application and validation of agent-based models, methods, and technologies in a number of key application areas, including: agent-oriented software engineering, conversations, motion coordination and unmanned aerial vehicles, Web and service systems, robotics exploration, smart cities and infrastructures, and social systems. Each paper submitted to PAAMS 2014 went through a stringent peer review by three members of the international committee composed of 97 internationally renowned researchers from 26 countries. From the 52 submissions received, 12 were selected for full presentation at the conference; another 14 papers were accepted as short presentations. In addition, a demonstration track featuring innovative and emergent applications of agent and multi-agent systems and technologies in real-world domains was organized. There were 19 demonstrations shown and this volume contains a description of each of them.

We would like to thank all the contributing authors, the members of the Program Committee, the sponsors (IEEE SMC Spain, IBM, AEPIA, AFIA, University of Salamanca and CNRS), and the Organizing Committee for their hard and highly valuable work. Their work helped contribute to the success of the PAAMS 2014 event. Thanks for your help - PAAMS 2014 would not exist without your contribution.

Yves Demazeau

Franco Zambonelli

Juan Manuel Corchado

Javier Bajo 


\section{Organization}

\section{General Co-chairs}

Yves Demazeau

Franco Zambonelli

Juan M. Corchado

Javier Bajo

\section{Advisory Board}

Frank Dignum

Toru Ishida

Jörg P. Müller

Juan Pavón

Michal Pěchouček

\section{Program Committee}

Emmanuel Adam

Carole Adam

Frederic Amblard

Francesco Amigoni

Javier Bajo

Jeremy Baxter

Michael Berger

Olivier Boissier

Vicente Botti

Lars Braubach

Stefano Bromuri

Longbing Cao

Javier Carbo

Luis Fernando Castillo

Lawrence Cavedon

Pierre Chevaillier

Caroline Chopinaud

Helder Coelho

Juan Manuel Corchado
Centre National de la Recherche Scientifique, France

University of Modena and Reggio Emilia, Italy University of Salamanca, Spain

Polytechnic University of Madrid, Spain

Utrecht University, The Netherlands

University of Kyoto, Japan

Technische Universität Clausthal, Germany

Universidad Complutense de Madrid, Spain

Czech Technical University in Prague,

Czech Republic

University of Grenoble, France

University of Grenoble, France

University of Toulouse, France

Politecnico di Milano, Italy

Polytechnic University of Madrid, Spain

QinetiQ, USA

Docuware AG, Germany

Ecole Nationale Superieure des Mines de Saint

Etienne, France

Polytechnic University of Valencia, Spain

Universität Hamburg, Germany

University of Applied Sciences Western

Switzerland, Switzerland

University of Technology Sydney, Australia

University Carlos III of Madrid, Spain

University of Caldas, Colombia

RMIT Melbourne, Australia

University of Brest, France

MASA Group, France

University of Lisbon, Portugal

University of Salamanca, Spain 
Vincent Corruble

Keith Decker

Alexis Drogoul

Julie Dugdale

Amal Elfallah Seghrouchni

Johannes Fähndrich

Jose Luis Fernandez

Marquez

Maksims Fiosins

Klaus Fischer

Rubén Fuentes

Javier Gil Quijano

Sylvain Giroux

Marie-Pierre Gleizes

Daniela Godoy

Jorge Gomez-Sanz

Vladimir Gorodetski

Charles Gouin-Vallerand

Salima Hassas

Vincent Hilaire

Koen Hindriks

Benjamin Hirsch

Martin Hofmann

Tom Holvoet

Shinichi Honiden

Jomi Fred Hubner

Toru Ishida

Takayuki Ito

Michal Jakob

Vicente Julian

Achilles Kameas

Takahiro Kawamura

Jeffrey Kephart

Stefan Kirn

Franziska Kluegl

Matthias Klusch

Martin Kollingbaum

Ryszard Kowalczyk

Jaroslaw Kozlak

Rene Mandiau
LIP6, Université Pierre et Marie Curie, (Paris 6), France

University of Delaware, USA

Institut de Recherche pour le Développement, Vietnam

University of Grenoble, France

University of Paris 6, France

Technische Universität Berlin / DAI Labor, Germany

University of Geneva, Italy

Clausthal University of Technology, Germany

DFKI, Germany

University Complutense de Madrid, Spain

CEA, LIST, LIMA, France

University of Sherbrooke, Canada

University of Toulouse, France

ISISTAN, Argentina

University Complutense de Madrid, Spain

University of Saint Petersburg, Russia

Télé-Université du Québec, Canada

Université Claude Bernard-Lyon1, France

UTBM, France

University of Delft, The Netherlands

Khalifa University, EBTIC, United Arab Emirates

Lockheed Martin, USA

Catholic University of Leuven, Belgium

National Institute of Informatics Tokyo, Japan

Universidad Federale de Santa Catarina, Brazil

University of Kyoto, Japan

Massachusetts Institute of Technology, USA

Czech Technical University in Prague, Czech Republic

Polytechnic University of Valencia, Spain

University of Patras, Greece

Toshiba, Japan

IBM T.J. Watson Research Center, USA

Universität Hohenheim, Germany

University of Örebro, Sweden

DFKI, Germany

University of Aberdeen, UK

Swinburne University of Technology, Australia

University of Science and Technology

in Krakow, Poland

University of Valenciennes, France 
Philippe Mathieu

Eric Matson

Felipe Meneguzzi

Fabien Michel

José M. Molina

Mirko Morandini

Jean-Pierre Muller

Jörg P. Müller

Victor Noel

Peter Novak

Akhihiko Ohsuga

Eugenio Oliveira

Andrea Omicini

Sascha Ossowski

Julian Padget

Juan Pavon

Paolo Petta

Sebastien Picault

Alessandro Ricci

Juan Antonio Rodriguez Aguilar

Jordi Sabater Mir

Silvia Schiaffino

Leonid Sheremetov

Jaime Sichman

Viviane Silva

Elizabeth Sklar

Graeme Stevenson

Sonia Suárez

Toshiharu Sugawara

Patrick Taillandier

Paolo Torroni

Rainer Unland

Domenico Ursino

László Zsolt Varga

Jacques Verriet

José Villar

Gerhard Weiss

Niek Wijngaards

Gaku Yamamoto
University of Lille, France

Purdue University, USA

PUCRS, Brazil

University of Reims, France

Universidad Carlos III de Madrid, Spain

University of Trento, Italy

CIRAD, France

Clausthal University of Technology, Germany

IRIT, France

Czech Technical University in Prague, Czech Republic

University of Electro-Communications, Japan

University of Porto, Portugal

University of Bologna, Italy

University of Rey Juan Carlos, Spain

University of Bath, UK

University Complutense de Madrid, Spain

University of Vienna, Austria

Equipe SMAC, (LIFL UMR 8022) - Université Lille 1, France

University of Bologna, Italy

AI Research Institute, Spain

IIIA-CSIC, Spain

ISISTAN, Argentina

Mexican Petroleum Institute, Mexico

University of Sao Paulo, Brazil

Universidade Federal Fluminense, Brazil

Brooklyn College, City University of

New York, USA

University of St. Andrews, UK

University of A Coruña, Spain

Waseda University, Japan

UMR IDEES, MTG, France

University of Bologna, Italy

University of Duisburg, Germany

University of Reggio Calabria, Italy

MTA SZTAKI, Hungary

Embedded Systems Institute, The Netherlands

University of Oviedo, Spain

University of Maastricht, The Netherlands

Thales, D-CIS lab, The Netherlands

IBM, Japan 


\section{Organizing Committee}

Juan M. Corchado (Chair)

Javier Bajo (Co-chair)

Juan F. De Paz

Sara Rodríguez

Dante I. Tapia

Fernando de la Prieta Pintado

Davinia Carolina Zato

Domínguez

Gabriel Villarrubia González

Antonio Juan Sánchez Martín
University of Salamanca, Spain

Polytechnic University of Madrid, Spain

University of Salamanca, Spain

University of Salamanca, Spain

University of Salamanca, Spain

University of Salamanca, Spain

University of Salamanca, Spain

University of Salamanca, Spain

University of Salamanca, Spain 
PAAMS 2014 Sponsors
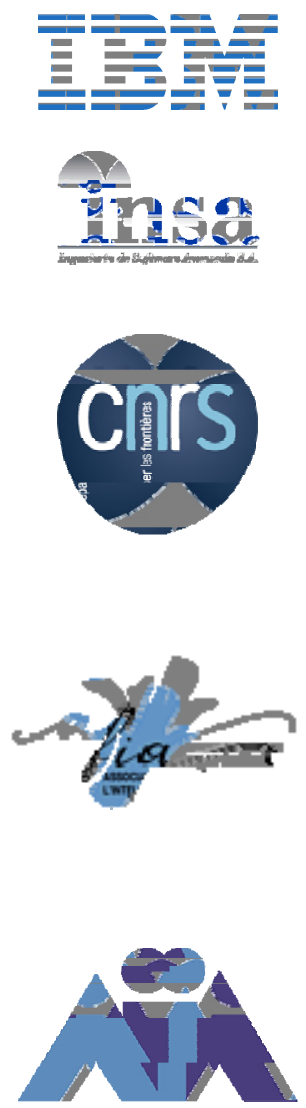

Indra

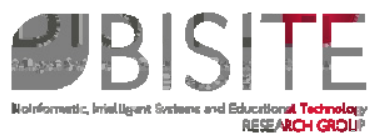

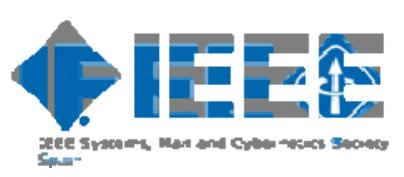

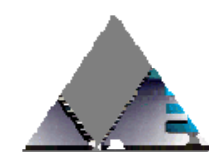

\section{Telefonica}

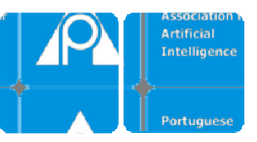

Junta de

custilla y leon

VNIVERSIDAD

D SALAMANCA

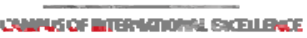




\section{Table of Contents}

\section{Regular Papers}

HPLAN: Facilitating the Implementation of Joint Human-Agent

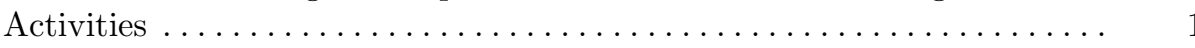

Sebastian Ahrndt, Philipp Ebert, Johannes Fähndrich, and

Sahin Albayrak

Reliable Multi-robot Map Merging of Inaccurate Maps.............

Ilze Andersone and Agris Nikitenko

Task-Oriented Conversational Behavior of Agents for Collaboration in Human-Agent Teamwork . . . . . . . . . . . . . . . . .

Mukesh Barange, Alexandre Kabil, Camille De Keukelaere, and Pierre Chevaillier

Agent-Based Simulation of Complex Aviation Incidents by Integrating

Different Cognitive Agent Models . . . . . . . . . . . . . . . . . . .

Tibor Bosse, Nataliya M. Mogles, and Jan Treur

A Multi-agent Based Optimised Server Selection Scheme for SOC

in Pervasive Environment ........................

Bikash Choudhury, Piyali Dey, Animesh Dutta, and

Subhrabrata Choudhury

Influence of Participation Rates and Service Level Differentiation

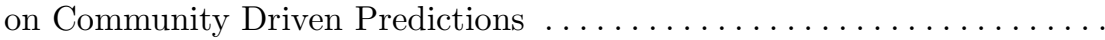

Rutger Claes, Katrien Van den Berghe, and Tom Holvoet

Anticipatory Coordination of Electric Vehicle Allocation to Fast

Charging Infrastructure . . . . . . . . . . . . . . . . . . .

Kristof Coninx, Rutger Claes, Stijn Vandael, Niels Leemput,

Tom Holvoet, and Geert Deconinck

Bilateral Negotiation of a Meeting Point in a Maze ..............

Fabien Delecroix, Maxime Morge, and Jean-Christophe Routier

Agent Negotiation for Different Needs in Smart Parking Allocation . . . . .

Claudia Di Napoli, Dario Di Nocera, and Silvia Rossi

Design of Forces Driving Adaptation of Agent Organizations . . . . . . . .

Sergio Esparcia, Olivier Boissier, and Estefanía Argente

Practical Multi-Agent System Application for Simulation of Tourists in Madrid Routes with INGENIAS .

Iván García-Magariño 
Domain and Subtask-Adaptive Conversational Agents to Provide an Enhanced Human-Agent Interaction . . . . . . . . . . . . . .

David Griol, José Manuel Molina, and Araceli Sanchís de Miguel

Dynamic Scheduling of Ready Mixed Concrete Delivery Problem Using

Delegate MAS . . . . . . . . . . . . . . . . . . . . . . . . . .

Shaza Hanif and Tom Holvoet

Handling Safety-Related Non-Functional Requirements in Embedded

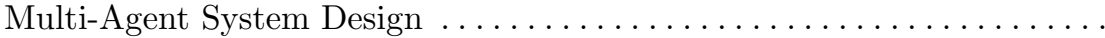

Jean-Paul Jamont, Clément Raievsky, and Michel Occello

The Multi-agent Patrolling Problem Theoretical Results about Cyclic

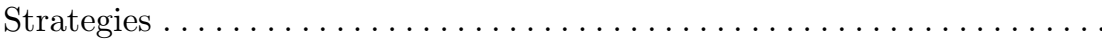

Fabrice Lauri, Jean-Charles Créput, and Abderrafiaa Koukam

Representation of Interactions in a Multi-Level Multi-Agent Model

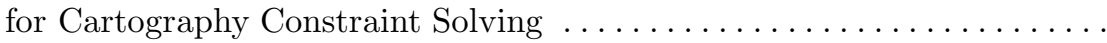

Adrien Maudet, Guillaume Touya, Cécile Duchêne, and Sébastien Picault

Practical Application of Matchmaking Problem: Trainee Allocation

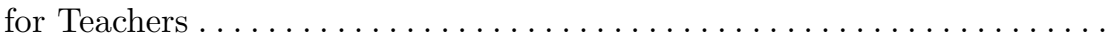

Maxime Morge and Eric Piette

A Control Architecture of Complex Systems Based on Multi-agent Models ................................

Tomás Navarrete Gutiérrez, Laurent Ciarletta, and Vincent Chevrier

Monitoring Oil Pipeline Infrastructures with Multiple Unmanned Aerial Vehicles... . . . . . . . . . . . . . . . . . . . . . . . . . . . . . .

Jakub Ondráček, Ondřej Vaněk, and Michal Pěchouček

Planning When Goals Change: A Moving Target Search Approach ..... .

Damien Pellier, Humbert Fiorino, and Marc Métivier

Agent Clusters: The Usual vs. The Unusual . . . . . . . . . . . . . . . .

Kavin Preethi Narasimhan and Graham White

An Agent-Based Architecture to Model and Manipulate Context

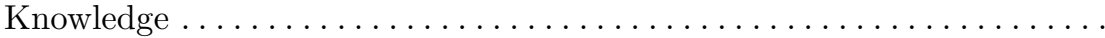

Ludo Stellingwerff and Giovanni E. Pazienza

Practical Applications of the Web-Based Agent Platform 'Eve'.........

Ludo Stellingwerff, Jos de Jong, and Giovanni E. Pazienza

Multi-Armed Bandit Policies for Reputation Systems

Thibaut Vallée, Grégory Bonnet, and François Bourdon 
MASSA: Multi-Agent System to Support Functional Annotation . . . . . . .

Daniela Xavier, Berta Crespo, Rubén Fuentes-Fernández, and Jorge J. Gómez-Sanz

A Multi-agent System for Nested Inquiry Dialogues 303

Chunli Yan, Juan Carlos Nieves, and Helena Lindgren

\section{Demo Papers}

The $\mathrm{C}^{2} \mathrm{BDI}$ Agent Architecture for Teamwork Coordination Using Spoken Dialogues between Virtual Agents and Users .............

Mukesh Barange, Alexandre Kabil, and Pierre Chevaillier

Agent Based Simulation for Creating Ambient Assisted Living

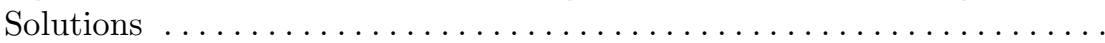

Pablo Campillo-Sanchez and Jorge J. Gómez-Sanz

A Microscopic Traffic Simulation Platform for Coordinated Charging of Electric Vehicles ............................. Kristof Coninx and Tom Holvoet

Bilateral Negotiation of a Meeting Point in a Maze: Demonstration . . . . . Fabien Delecroix, Maxime Morge, and Jean-Christophe Routier

Using Negotiation for Parking Selection in Smart Cities . . . . . . . . . . .

Claudia Di Napoli, Dario Di Nocera, and Silvia Rossi

Developing Multimodal Conversational Agents: From the Use of VoiceXML to Android-Based Applications . . . . . . . . . . . . .

David Griol, José Manuel Molina, and Araceli Sanchís de Miguel

Addressing Large Scale and Dynamic Scheduling by Nature Inspired

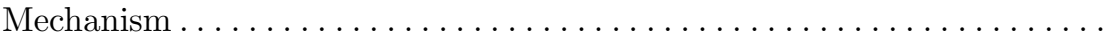

Shaza Hanif, Shahab Ud Din, and Tom Holvoet

Illustrating an Intuitive and Informative Learning Platform for Third Level Education ..................................

Olapeju Latifat Ayoola and Eleni Mangina

A Federation Layer for Query Processing over the Web of Linked

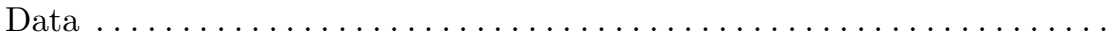

Xuejin Li, Zhendong Niu, Chunxia Zhang, and Junyue Cao

Market Garden: A Simulation Environment for Research and User Experience in Smart Grids . . . . . . . . . . . . . . . . . .

Bart Liefers, Felix N. Claessen, Eric Pauwels, Peter A.N. Bosman, and Han La Poutré 
Multi-agent Multi-level Cartographic Generalisation in CartAGen . . . . . .

Adrien Maudet, Guillaume Touya, Cécile Duchêne, and Sébastien Picault

An Agent-Based Approach for the Design of the Future European Air Traffic Management System . . . . . . . . . . . . . . . . . . . . . . . . . Martin Molina, Jorge Martin, and Sergio Carrasco

Multi-robot System for Vacuum Cleaning Domain . 363 Agris Nikitenko, Janis Grundspenkis, Aleksis Liekna, Martins Ekmanis, Guntis Kulikovskis, and Ilze Andersone

receteame.com: A Persuasive Social Recommendation System ......... 367 Javier Palanca, Stella Heras, Vicente Botti, and Vicente Julián

Automatic Electricity Markets Data Extraction for Realistic Multi-agent Simulations

Ivo F. Pereira, Tiago M. Sousa, Isabel Praca, Ana Freitas, Tiago Pinto, Zita Vale, and Hugo Morais

Look, Who's Talking: Simulations of Agent Clusters . . . . . . . . . . . Kavin Preethi Narasimhan and Graham White

Developing Intelligent Virtual Environments Using MAM5 Meta-Model ................................

J.A. Rincon, Carlos Carrascosa, and Emilia Garcia

Multi-agent Platform for Designing Real Time Adaptive Scheduling Systems . . . . . . . . . . . . . . . . . . . . . . .

Petr Skobelev, Denis Budaev, Vladimir Laruhin, Evgeny Levin, and Igor Mayorov

An Agent-Managed Ad-hoc Social Network to Facilitate F2F

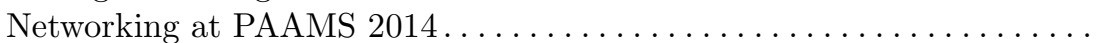

Ludo Stellingwerff and Giovanni E. Pazienza

Author Index . 